\title{
Analysis of manufacturing systems using simulations in terms of material flow cost accounting
}

\author{
Soemon Takakuwa* \\ Graduate School of Economics and Business Administration, Nagoya University \\ Nagoya, 464-8601, JAPAN \\ E-mail: takakuwa@soec.nagoya-u.ac.jp \\ Run Zhao ${ }^{\dagger}$ \\ Economics \& Management School, Jiangsu University of Science and Technology \\ Zhenjiang, 212003, CHINA \\ E-mail: zhaorun1982@hotmail.com \\ Hikaru Ichimura* \\ Graduate School of Economics and Business Administration, Nagoya University \\ Nagoya, 464-8601, JAPAN \\ E-mail: ichimura.hikaru@f.nagoya-u.jp
}

Received 19 January 2014

Accepted 17 March 2014

\begin{abstract}
Material flow cost accounting (MFCA), an environmental management accounting method, is adopted to reduce the amount of wastes that result from manufacturing activities. In this paper, MFCA is introduced to study the environmental impacts of production lot-size determination by structuring simulation models of a multi-variety and small-batch production system in an actual forging factory. It is demonstrated that the proposed procedure of application of simulation with MFCA can also perform a dynamic analysis and a static analysis.
\end{abstract}

Keywords: Manufacturing System, Simulation, Material Flow Cost Accounting, ISO, Environmental Management.

\section{Introduction}

Daily life and economic activities are closely related to the global environment. With the vast depletion of natural resources and energy, high levels of emissions of carbon dioxide and other greenhouse gases, coupled with a significant amount of waste, are released in the environment, thus creating a continuously increasing environmental burden that negatively impacts our daily lives and economic activities. Mitigating the adverse effects of business operations on the natural environment is the main goal of environmental management.
In this paper, Material Flow Cost Accounting (MFCA) is adopted, to reduce the amount of waste that results from manufacturing activities. MFCA was internationally standardized as ISO 14051 in September 2011 and compatible with ISO 9000 standards. MFCA focuses on material flow and emphasizes those nonproduct outputs or material losses are also products of the same manufacturing process. Within the MFCA framework, costs are calculated for not only good products but also non-product outputs or material losses. The former is referred to as "positive products," and the latter, as "negative products." MFCA visualizes the cost

*Furo-cho, Chikusa-ku, Nagoya, Aichi 464-8601, JAPAN.

${ }^{\dagger}$ Mengxi Road No.2, Zhenjiang City, 212003, Jiangsu Province, CHINA. 
of producing non-product outputs or material losses and thus highlights areas of potential improvement. ${ }^{1,2}$

Although MFCA is powerful as an environmental management tool, it can perform only static analysis. Hence, this paper proposes that dynamic analysis as well as static analysis can be performed by constructing simulation models for the designated manufacturing systems and performing simulation analysis in terms of MFCA. A Real example is introduced for a forging manufacturing system which involves seven processes.

\section{MFCA}

\subsection{Outline of MFCA}

Fig. 1 illustrates the concept of MFCA that traces all input materials flowing through production processes and measures output in the finished products and waste. In a processing-type production system, waste is generated in various steps of the production process. In particular, in the process of stocking and production, a substantial amount of waste is produced because materials and intermediate products that are overstocked as inventory may deteriorate in quality or be discarded. Additionally, while materials or intermediate products are processed, residues or shavings may be generated. All wastes mentioned above are called "negative products" and contribute to an environmental burden. In MFCA, the idle processing, unnecessary energy and auxiliary material consumption caused during the waste generation are also called "negative products" and are treated as environmental costs.

\subsection{Applications of MFCA}

The Ministry of Economy, Trade and Industry (METI) in Japan has been encouraging Japanese companies to introduce MFCA into their management systems. MFCA is a system to measure the flows and stocks of materials in the manufacturing process in terms of physical and monetary units. METI suggests the following possibilities of improvement by the MFCA ${ }^{4}$ :

(I) Increased production efficiency from capital investment;

(II) Cost reduction by changing product designs and raw materials;

(III) Extensibility to supply chain and social costs;

(IV) Providing specific targets for on-site improvement activities such as TQC (Total Quality Control) and ISO.

MFCA can also be applied to the supply chain. It is necessary to define an environmentally friendly supply chain, to potentially measure the effect, and to establish a scheme for evaluating such supply chains. ${ }^{2}$ Recently, MFCA in particular has received considerable attention for its effectiveness in improving both productivity and the harmony of environmental profitability. ${ }^{5}$

The effectiveness of the in-process type of management technique of MFCA is confirmed by constructing a simulation model using the MFCA concept. ${ }^{6,7}$ In addition, it is determined that companies adopting MFCA can improve their decision-making procedures and advantageously alter their manufacturing methods using a strategy that differs from the inventory reduction logic based on the traditional Toyota production system. ${ }^{8}$

In this paper, MFCA is introduced to study the environmental impacts of production lot-size determination by structuring simulation models in a multi-variety and small-batch production system. By applying MFCA, significant invisible wastes (called "negative products" in MFCA) caused by inaccurate determinations of production lot-size are identified. These wastes, or negative products, generate large amounts of environmental burdens because of unusable overstock and idle processing.

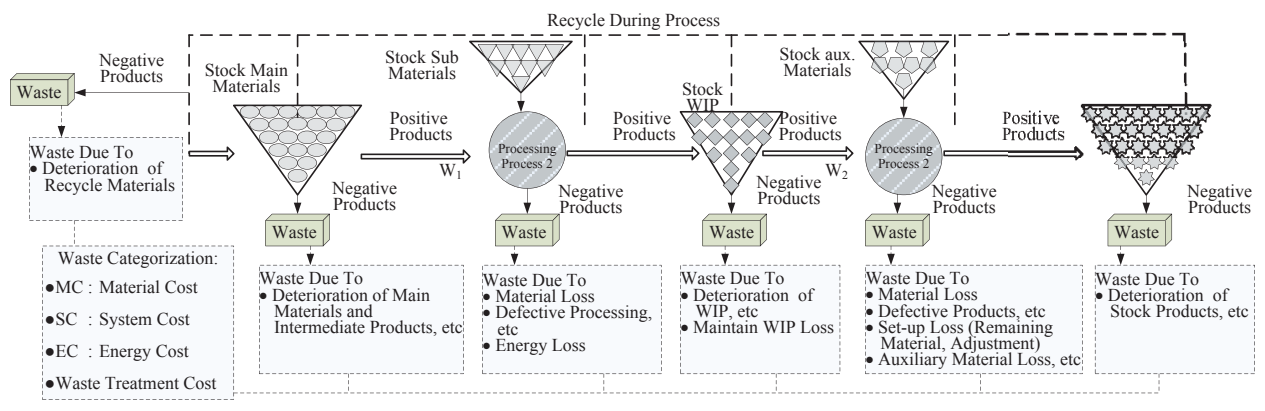

Fig. 1. The concept of MFCA ${ }^{3}$. 


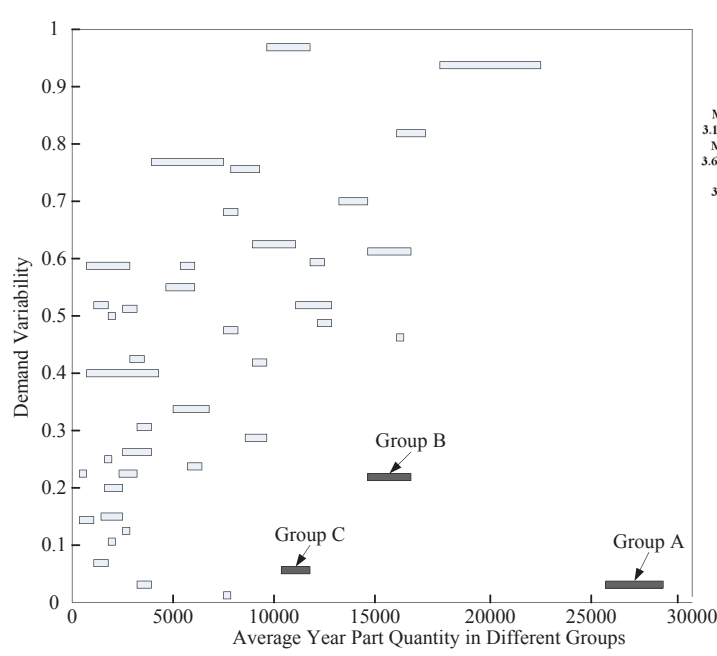

(a) Sample Plot of Multiple Part Types by Quantity and Demand Variability

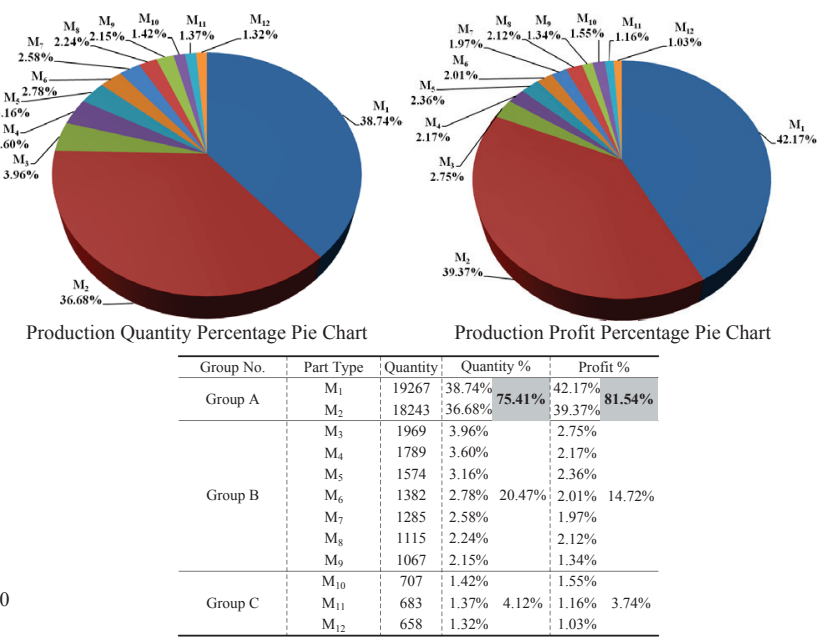

(b) Part Quantity and Profit Percentage of Main Types

Fig.2. Relative statistical data on multiple part types from the current production.

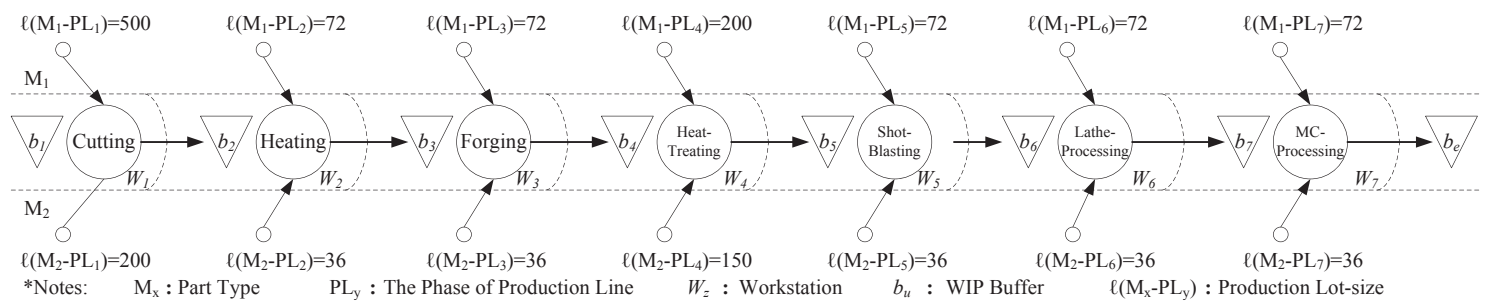

Fig. 4. Logical structure of production line for part types $M_{1}$ and $M_{2}$.

\section{Applications}

\subsection{Manufacturing system description}

This paper considers a real case of a multi-variety and small-batch production system, which is located in a precision component manufacturing workshop of a Japanese company. To satisfy diverse demands from different customers, hundreds of part types are produced, and corresponding production lines are designed. As Fig. 2 (a) shows, the part types are divided into tens of groups because of changes in market needs. Parts in groups A, B and C have a large production quantity and lower demand variability compared to the other groups. The economic benefit and productivity of these part types is crucial to the entire system. Fig. 2 (b) shows that parts in group A account for over $75 \%$ of production quantity and $80 \%$ of profits. Consequently, in this paper, part types $\mathrm{M}_{1}$ and $\mathrm{M}_{2}$, both shown in Fig. 3 , composing group $\mathrm{A}$, are selected as the research object. The study of the environmental problems for these part types will also provide some suggestions for the other part types.

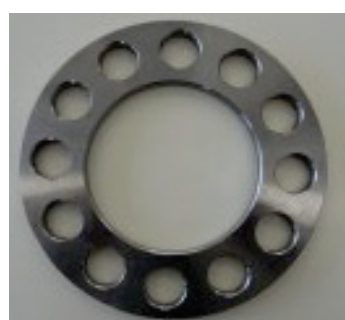

$\mathrm{M}_{1}$

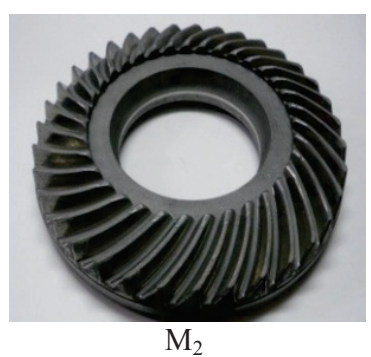

$\mathrm{M}_{2}$
Fig. 3. Designated parts.

Fig. 4 shows the logical structure of the current production line for part types $\mathrm{M}_{1}$ and $\mathrm{M}_{2}$. This production line mainly comprises seven workstations. To fulfill the requirements of part type diversification and rapid responses to market needs, different small production lot-sizes for $\mathrm{M}_{1}$ and $\mathrm{M}_{2}$ are used for each workstation and are denoted $\mathrm{M}_{\mathrm{x}}-\mathrm{PL}_{\mathrm{y}}$. In the HeatTreating Station and Shot-Blasting Station, processing begins only when a number of parts equal to the preestablished production lot-size have all arrived. For the other stations, however, the parts are processed one by one. 


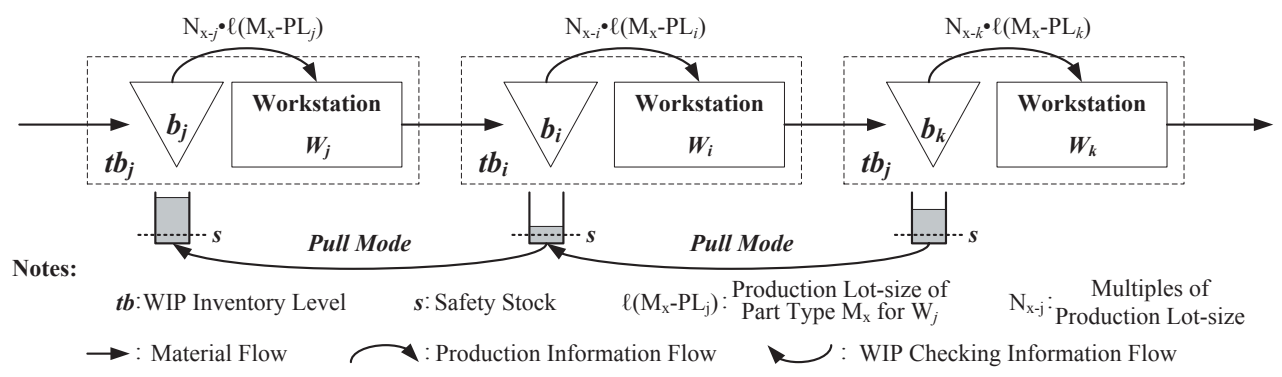

Fig. 5. The logic of the Pull production mode based on an inventory level rule.

\subsection{Production operation mechanism}

This production system is operated in Pull mode based on an inventory level decision-making mechanism. For one part type, when the order is arriving, the managers will first check the finished product inventory $\left(\boldsymbol{b}_{\boldsymbol{e}}\right)$ to determine whether the stock is large enough to provide the quantity ordered. If the order can be fulfilled, a corresponding quantity of parts will be delivered to the customer. If the order cannot be filled, the upstream Work-In-Process (WIP) inventory $\left(\boldsymbol{b}_{7}\right)$ of the last workstation $\left(\boldsymbol{W}_{7}\right)$ will be checked. In addition, for the last workstation $\boldsymbol{W}_{7}$, a certain quantity of intermediate products of multiple production lot-sizes from $\boldsymbol{b}_{7}$ will be processed to meet the shortage of be. This approach is called a back scheduling for the production system operation. All of the checking work and production will thus be stopped until a certain upstream WIP inventory level $\left(\boldsymbol{b}_{\boldsymbol{i}}\right)$ of a certain workstation $\left(\boldsymbol{W}_{\boldsymbol{i}}\right)$ can fulfill the shortage of a certain downstream WIP inventory level $\left(\boldsymbol{b}_{j}\right)$ for workstation $\left(\boldsymbol{W}_{\boldsymbol{j}}\right)$ production. Moreover, safety stock $\mathrm{s}$ is considered, and each WIP inventory level should be larger than $\mathrm{s}$ after determining the production quantity for the downstream workstation. Considering the design requirements of the production line and setup-time reduction, the production quantity for each workstation is multiple production lot-sizes. Figure 5 shows the logic for this Pull production mode.

\subsection{Simulation model of manufacturing system}

\subsubsection{Simulation model}

Based on the structure of the real production system, a simulation model called the AS-IS model is constructed to analyze the current production problems. The AS-IS model facilitates introducing MFCA to the production system to identify hidden environmental problems effectively over a long running time. This study uses the Arena simulation platform ${ }^{9}$ to develop this AS-IS model comprising four parts, as shown in Fig. 6.

\subsubsection{Logic of the simulation model}

Fig. 7 shows the main simulation logic for the AS-IS model. The first part is the Order Arriving submodel, designed to simulate the arrivals of orders and to randomly create the production quantities required by each order. The second part is the $\mathrm{M}_{1} / \mathrm{M}_{2}$ Production Plan submodel, designed to create a production plan and production lot-size determination for each workstation according to the Pull mode, based on an inventory level decision-making rule. The third part includes seven processing submodels, designed to implement the production plan. The last part is the Parts Leaving submodel, used to develop the necessary statistics to analyze production system performance.

\section{Simulation Analysis Using the Concept of MFCA}

A reasonable production lot-size determination is crucial for production management. The study of production lot-size determination has thus received considerable attention from researchers recently. Azaron et al. developed a stochastic dynamic optimal programming algorithm for obtaining dynamic economic lot-size. ${ }^{10}$ Nirmal and Tapan used multiobjective geometric programming to develop a multiitemfinite production lot-size model. ${ }^{11}$ Kämpf and Köchel used simulation optimization with a genetic algorithm as an optimizer to identify the optimal production lot-size. ${ }^{12}$ However, these studies focused on obtaining an optimal algorithm for determining production lot-size, seldom considering the aspects of environmental performance. 


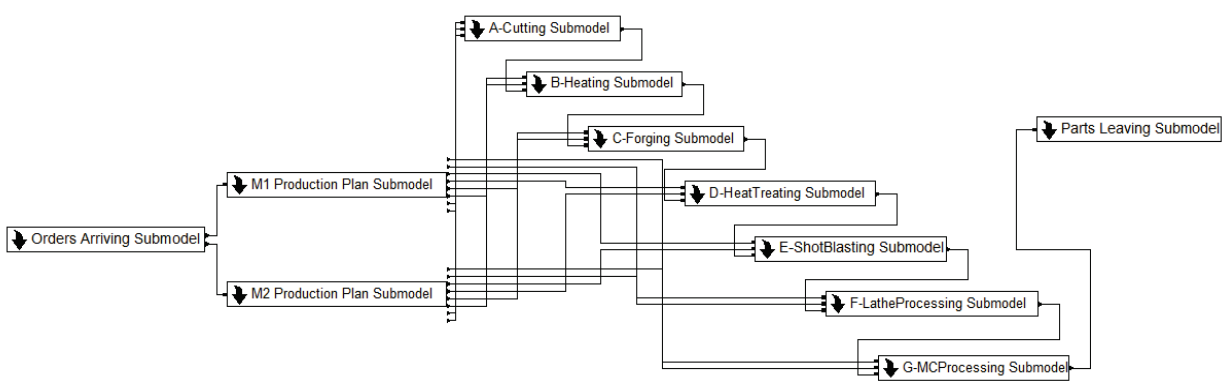

Fig. 6. AS-IS simulation model.

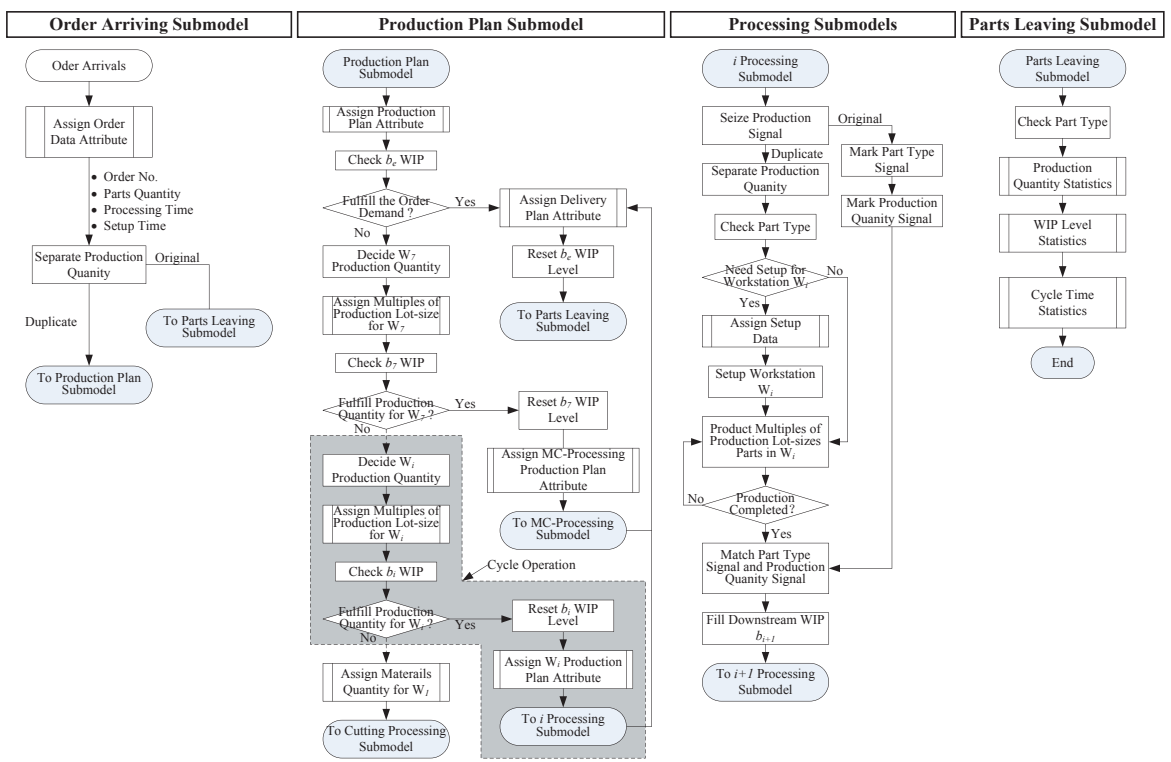

Fig. 7. The main simulation logic of the AS-IS model based on back scheduling.

Different production lot-size will produce different WIP inventory levels for different production stages. Hence, a sensitivity analysis is used to analyze the changes in the negative products cost resulting from the regulation of production lot-size.

Negative products cost of a unit part by regulating production lot-size is shown in Fig. 8. From Fig. 8, it can be observed that the negative products cost of a unit part changes. With increasing production lot-size, for the unit part, the average negative products cost changes along a declining curve. In one respect, this situation obeys the mass production mode that increasing the production lot-size generally reduces costs. The following are environmental considerations. First, through simulation monitoring and tracing with the MFCA method, the remaining overstock in inventory and the unusable idle processing corresponding to each production lot-size point are identified. Second, inapposite production lot-size generates substantial scrap and waste, thereby increasing the negative products and the environmental costs that are invisible during the production process and are easily overlooked by the conventional cost accounting method. Third, corresponding to the parts quantity distribution for the current order demand of each part type, there exists a relative appropriate production lot-size with the lowest negative products cost. Fourth, large increasing negative environmental costs will be reduced by increasing production lot size by, for example, using mass production mode. Final, in the real production system, the similar change curve for different part types in different processes will be changed because of various real random production factors, and the corresponding value will increase or decrease. 


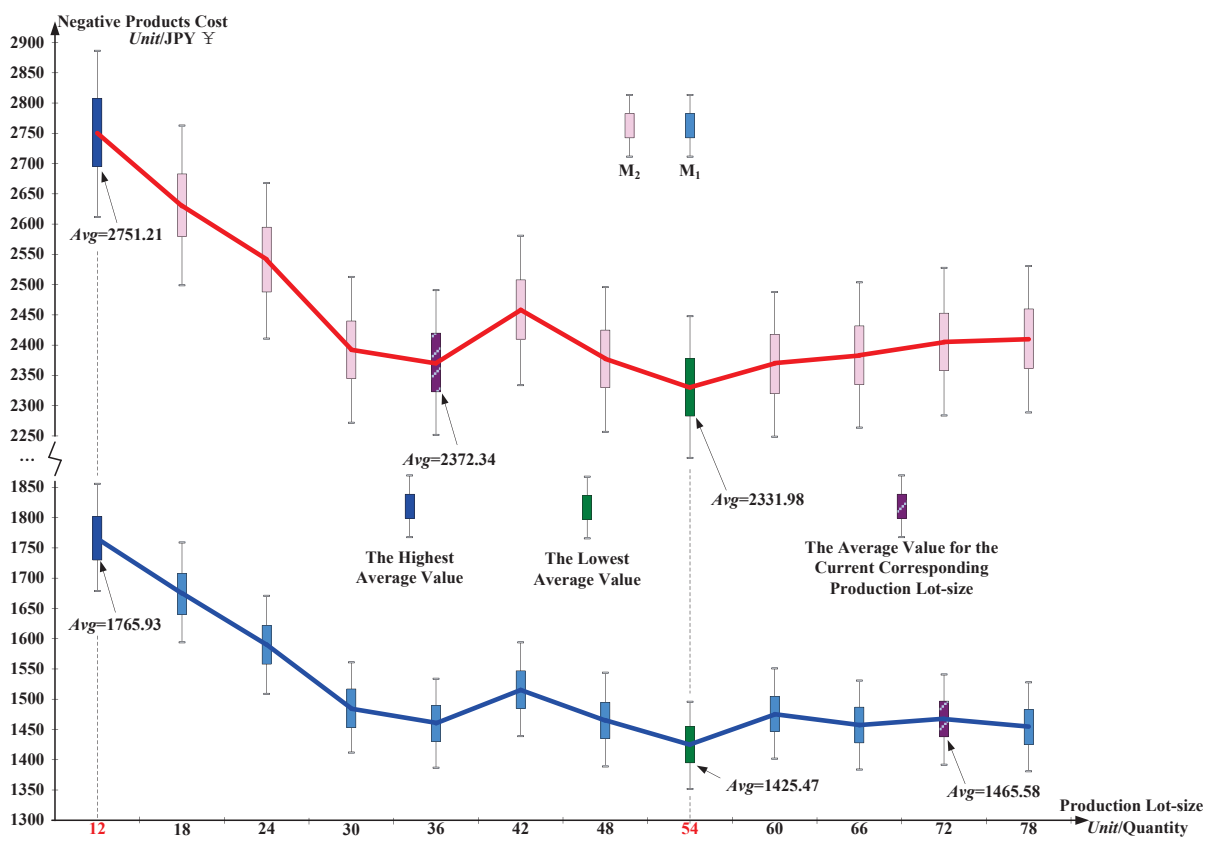

Fig. 8. Negative products cost of a unit part by regulating production lot-size.
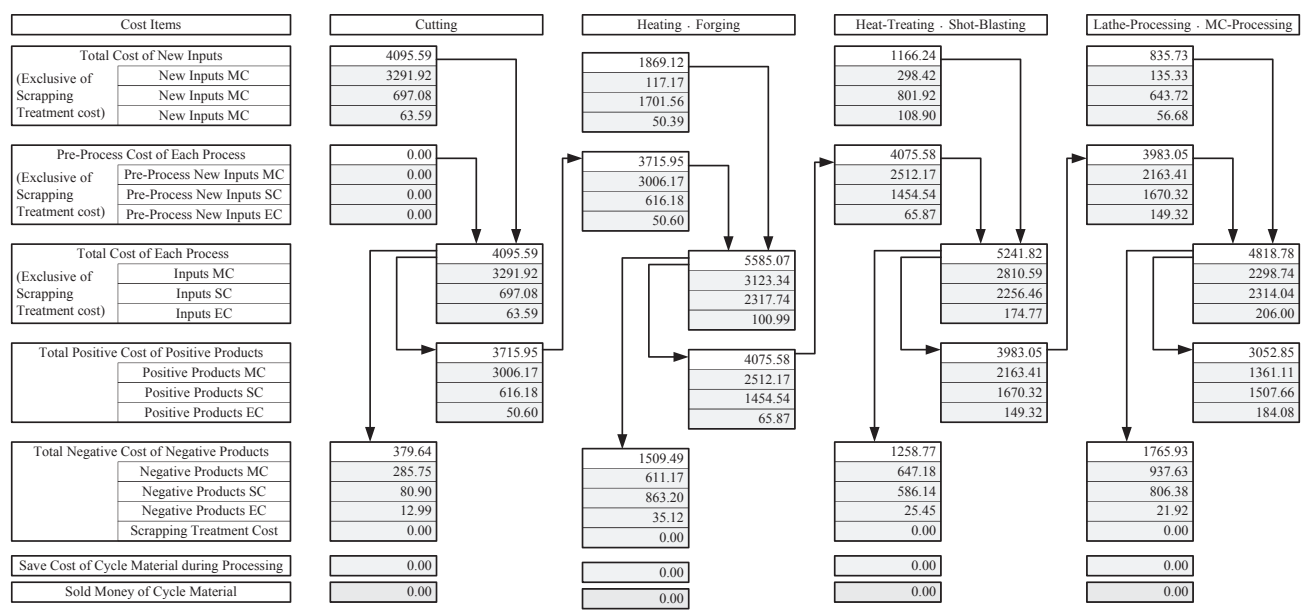

Fig. 9. MFCA flowchart including calculation data $\left(\mathrm{M}_{1}\right.$-Lot Size=12）(Unit/JPY ¥).

Furthermore, Fig. 8 shows that the lowest or highest average negative cost value for different part types has a corresponding production lot size. To understand the concept of MFCA and apply calculation processes, an example is developed. Part $\mathrm{M}_{1}$ is selected, and an extreme value situation (i.e., production lot sizes of 12) are considered, as shown in Fig. 9. Based on the MFCA, the abandonment of the dead WIP stocks, unusable materials and idle processing are reflected as the generation of negative products cost in terms of monetary units, which are invisible during production. However, from these MFCA flowcharts, the actual wastes and negative product costs generated during the production process are identified and clearly understood.

The AS-IS model is reconstructed to introduce the concept of MFCA by embedding a Monitor submodel, called the AS-IS-NC Model. All production operations are monitored, and all material flows are traced by this submodel. 
Table 1 shows Part M1Cost results of the unit part by comparing the AS-IS-NC model and the AS-IS model for two extreme values (i.e., production lot sizes of 12 and 54). This table shows that different lot sizes will create different negative product costs that cannot be identified by a traditional cost accounting method. Additionally, a high lot size generates lower negative product costs.

The final results of the AS-IS-NC simulation model are compared with those of the AS-IS model for two part types in Table 2. Using MFCA can reveal invisible costs in the production processes; in particular, the negative products cost referring to environmental impacts becomes visible. For each unit part in the ASIS-NC model, the negative products cost of $\mathrm{M}_{1}$ constitutes $36.65 \%$ of the total cost, and the negative products cost of $\mathrm{M}_{2}$ constitutes $30.64 \%$ of the total cost. Because the negative products cost is invalid for this production case, these high percentages indicate that the determination strategy for the production lot-size must be analyzed and improved to reduce the environmental burden by maintaining a low WIP inventory level.

Table $1 . \mathrm{M}_{2}$ Cost results of unit part by comparing the AS-IS-NC model and the AS-IS model.

\begin{tabular}{|c|c|c|c|c|c|c|c|c|c|c|}
\hline \multicolumn{5}{|c|}{ AS-IS Simulation Model } & \multicolumn{6}{|c|}{ AS-IS-NC Simulation Model } \\
\hline \multirow{2}{*}{$\begin{array}{l}\text { Conventional Cost } \\
\text { Accounting }\end{array}$} & \multicolumn{2}{|c|}{ Lot Size $=12$} & \multicolumn{2}{|c|}{ Lot Size $=54$} & \multirow{2}{*}{\multicolumn{2}{|c|}{ MFCA }} & \multicolumn{2}{|c|}{ Lot Size $=12$} & \multicolumn{2}{|c|}{ Lot Size $=54$} \\
\hline & $\operatorname{Avg}$ & $S D$ & $\operatorname{Avg}$ & $S D$ & & & $\operatorname{Avg}^{(1)}$ & $S D^{(2)}$ & Avg & $S D$ \\
\hline \multirow{4}{*}{ Materials Cost } & \multirow{4}{*}{2974.21} & \multirow{4}{*}{24.45} & \multirow{4}{*}{2177.08} & \multirow{4}{*}{26.13} & \multirow{4}{*}{$\begin{array}{c}\text { Positive } \\
\text { Products Cost }\end{array}$} & $\mathrm{MC}$ & 1361.11 & 10.13 & 1098.85 & 15.23 \\
\hline & & & & & & $\mathrm{SC}$ & 1507.66 & 12.74 & 1217.17 & 19.17 \\
\hline & & & & & & $\mathrm{EC}$ & 184.08 & 2.06 & 148.61 & 2.02 \\
\hline & & & & & & $\mathrm{TPC}^{(3)}$ & 3052.85 & 27.57 & 2464.63 & 21.15 \\
\hline \multirow{4}{*}{ Process Cost } & \multirow{4}{*}{1844.57} & \multirow{4}{*}{20.93} & \multirow{4}{*}{1713.22} & \multirow{4}{*}{23.77} & \multirow{4}{*}{$\begin{array}{c}\text { Negative } \\
\text { Products Cost }\end{array}$} & $\mathrm{MC}$ & 937.63 & 14.76 & 756.97 & 20.90 \\
\hline & & & & & & $\mathrm{SC}$ & 806.38 & 18.00 & 651.01 & 27.76 \\
\hline & & & & & & $\mathrm{EC}$ & 21.92 & 0.67 & 17.69 & 0.41 \\
\hline & & & & & & \multicolumn{2}{|c|}{$\mathrm{TNC}^{(4)} 1765.93$} & 24.69 & 1425.67 & 25.78 \\
\hline Total Cost & 4818.78 & 51.66 & 3890.3 & 41.94 & TPC & & 4818.78 & 41.88 & 3890.3 & 39.14 \\
\hline
\end{tabular}

Table 2. Cost results of unit part by comparing the AS-IS-NC model and the AS-IS model.

\begin{tabular}{|c|c|c|c|c|c|c|c|c|c|c|}
\hline \multicolumn{5}{|c|}{ AS-IS Simulation Model } & \multicolumn{6}{|c|}{ AS-IS-NC Simulation Model } \\
\hline \multirow{2}{*}{$\begin{array}{l}\text { Conventional Cost } \\
\text { Accounting }\end{array}$} & \multicolumn{2}{|c|}{$\mathrm{M}_{1}$} & \multicolumn{2}{|c|}{$\mathrm{M}_{2}$} & \multirow{2}{*}{\multicolumn{2}{|c|}{ MFCA }} & \multicolumn{2}{|c|}{$\mathrm{M}_{1}$} & \multicolumn{2}{|c|}{$\mathrm{M}_{2}$} \\
\hline & Avg & $S D$ & Avg & $S D$ & & & $A v g^{(1)}$ & $S D^{(2)}$ & Avg & $S D$ \\
\hline \multirow{4}{*}{ Materials Cost } & \multirow{4}{*}{2009.77} & \multirow{4}{*}{14.45} & \multirow{4}{*}{3658.36} & \multirow{4}{*}{31.71} & \multirow{4}{*}{$\begin{array}{c}\text { Positive } \\
\text { Products Cost }\end{array}$} & $\mathrm{MC}$ & 1129.61 & 14.45 & 2240.19 & 31.71 \\
\hline & & & & & & $\mathrm{SC}$ & 1251.24 & 18.50 & 2717.67 & 39.95 \\
\hline & & & & & & $\mathrm{EC}$ & 152.77 & 2.22 & 411.87 & 4.82 \\
\hline & & & & & & $\overline{\mathrm{TPC}^{(3)}}$ & 2533.62 & 32.17 & 5369.73 & 49.55 \\
\hline \multirow{4}{*}{ Process Cost } & \multirow{4}{*}{1989.43} & \multirow{4}{*}{20.93} & \multirow{4}{*}{ 4083.71: 12} & \multirow{4}{*}{43.28} & \multirow{4}{*}{$\begin{array}{c}\text { Negative } \\
\text { Products Cost }\end{array}$} & $\mathrm{MC}$ & 778.16 & 11.76 & 1318.17 & 20.90 \\
\hline & & & & & & $\mathrm{SC}$ & 669.23 & 17.00 & 971.21 & 27.76 \\
\hline & & & & & & $\mathrm{EC}$ & 18.19 & 0.07 & 82.96 & 0.41 \\
\hline & & & & & & $\overline{\mathrm{TNC}^{(4)}}$ & 1465.58 & 20.69 & 2372.34 & 25.78 \\
\hline \multirow{2}{*}{ Total Cost } & \multirow{2}{*}{3999.2} & \multirow{2}{*}{27.66} & \multirow{2}{*}{7742.07} & \multirow{2}{*}{68.47} & Total Cos & & 3999.2 & 41.88 & 7742.07 & 59.14 \\
\hline & & & & & TNC-P(5) & & \multicolumn{2}{|c|}{$36.65 \%$} & \multicolumn{2}{|c|}{$30.64 \%$} \\
\hline
\end{tabular}

An AS-IS model is constructed to simulate a case study of a multi-variety and small-batch production system. Overdue WIP overstocks and defective WIP intermediate products are scrapped in abundance, thus causing a significant environmental burden that is not addressed by conventional cost accounting. However, the effectiveness of a new environmental accounting method called MFCA is confirmed by constructing an AS-IS-NC simulation model and thus by introducing the MFCA concepts. Based on MFCA, the abandonment of dead WIP stocks, unusable materials and idle processing are reflected as the generation of negative products cost in terms of monetary units that are invisible during production, as shown in Fig. 9 and Fig. 10.
Additionally, after comparing the AS-IS-NC model and the AS-IS model, large negative products costs and environmental costs caused by the current production lot-size determination policy are identified. Running several different simulation scenarios yields a simulation analysis to analyze the changes in the negative products cost resulting from the regulation of the production lot-size. After observing the characteristics of change curves while gradually regulating the production lot-size, the declining change trend in negative products cost provides production managers with effective and strategic knowledge for determining appropriate production lot-size to maintain 
a low WIP inventory level and for considering both economic and environmental benefits.

\section{Conclusions}

Using the concept of MFCA, a simulation analysis is performed to reduce the amount of wastes resulting from manufacturing activities. Within the framework of Material Flow Cost Analysis, costs are calculated for not only good products but also non-product outputs or material losses "negative products." A real case of a certain multi-variety and small-batch production system in a precision component manufacturing workshop of a Japanese company is presented. A simulation-based MFCA approach is adopted to study the environmental impacts of production lot-size determination for a multivariety and small-batch production system in an actual forging factory. By applying the proposed approach, significant invisible wastes caused by inaccurate determinations of production lot-size are identified. It is demonstrated that the proposed procedure of application of simulation in terms of MFCA can also perform a dynamic simulation analysis along with a static analysis performed by using MFCA to increase production efficiency.

\section{References}

1. K. Kokubu, Material Flow Cost Accounting (Tokyo: Japan Environmental Management Association for Industry, 2008). (In Japanese)

2. K. Kokubu and H. Tachikawa, "Material Flow Cost Accounting" (Chapter 8), In Manufacturing and Environmental Management, Edited by S. Takakuwa, pp. 265-283. (National Political Publishing House, ISBN: 978-604-57-0000-6, Hanoi, 2012).

3. Environmental Industries Office (Industrial Science and Technology Policy and Environment Bureau, Ministry of Economy, Trade and Industry, Japan, 2007 (a)). "Guide for Material Flow Cost Accounting (Ver.1)" http://www.meti.go.jp/policy/eco_business/pdf/mfca\%20 guide20070822.pdf.

4. Environmental Industries Office (Industrial Science and Technology Policy and Environment Bureau, Ministry of Economy, Trade and Industry, Japan, 2007 (b)). "Environmental Management Accounting (Material Flow Cost Accounting: MFCA)"http://www.meti.go.jp/policy/eco_business/pdf/ EMA(MFCA)-english\%20ppt.pdf

5. M. Nakajima, Evolution of Material Flow Cost Accounting (MFCA): Characteristics on Development of MFCA Companies and Significance of Relevance of
MFCA (Kansai University of Business and Commerce, 2009), pp. 27-46.

6. X. Tang and S. Takakuwa, Simulation Analysis for ERP Conducted in Japanese SMEs Using the Concept of MFCA, In Proceedings of the 2011 Winter Simulation Conference, Edited by S. Jain, R.R. Creasey, J. Himmelspach, K.P. White, and M. Fu (Piscataway, New Jersey: Institute of Electrical and Electronics Engineers, Inc., 2011), pp. 1084-1095.

7. X. Tang and S. Takakuwa, MFCA-based Simulation Analysis for Environment-oriented SCM Optimization Conducted by SMEs, In Proceedings of the 2012 Winter Simulation Conference, Edited by C. Laroque, J. Himmelspach, R. Pasupathy, O. Rose, and A.M. Uhrmacher (Piscataway, New Jersey: Institute of Electrical and Electronics Engineers, Inc., . 2011), pp. 1716-1726.

8. H. Ichimura and S. Takakuwa, Decision-making method of production systems that contribute to environmental management thinking from the perspective of material flow cost accounting, In Proceedings of the 2013 Winter Simulation Conference, Edited by R. Pasupathy, S-H. Kim, A.Tolk, R. Hill and M. E. Kuh (Piscataway, New Jersey: Institute of Electrical and Electronics Engineers, Inc., 2013), pp. 1973-1983.

9. W. D. Kelton, R. P. Sadowski and N. B. Swets, Simulation with ARENA. $5^{\text {th }}$ ed. (McGraw-Hill, Inc., New York, 2010.)

10. A. Azaron, O. Tang and R. M. Tavakkoli, Dynamic Lot Sizing Problem with Continuous-time Markovian Production Cost, J. International Journal of Production Economics 120(2) (2009) 607-612.

11. K. M. Nirmal and K. R. Tapan, Multi-item Imperfect Production Lot Size Model with Hybrid Number Cost Parameters, J. Applied Mathematics and Computation 182(2) (2006) 1219-1230.

12. M. Kämpf and P. Köchel, Simulation-based Sequencing and Lot Size Optimization for A Production-andInventory System with Multiple Items, J. International Journal of Production Economics 104(1) (2006) 191-200.

\section{Acknowledgments}

The authors wish to express their sincere gratitude to Mr. Y. Watanabe of Metal Worker Toa \& Arai Company, Ltd. and Mr. Y. Murata of Fujita Health University for their cooperation in this research. Special thanks should be given to Prof. K. Kokubu of Kobe University for his suggestion on MFCA. This research was supported by the Grant-in-Aid of the Japan Society for the Promotion of Science (JSPS). 